Hongling Xiao*, Roeland W. N. M. van Hout, Ted J. M. Sanders and Wilbert P. M. S. Spooren

\title{
A cognitive account of subjectivity put to the test: using an insertion task to investigate Mandarin result connectives
}

\author{
https://doi.org/10.1515/cog-2020-0075 \\ Received June 30, 2020; accepted September 11, 2021; published online October 20, 2021
}

\begin{abstract}
This article aims to further test the cognitive claims of the so-called subjectivity account of causal events and their linguistic markers, causal connectives. We took Mandarin Chinese, a language that is typologically completely different from the usual western languages, as a case to provide evidence for this subjectivity account. Complementary to the commonly used corpora analyses, we employed crowdsourcing to tap native speakers' intuitions about causal coherence, focusing on four result connectives kějiàn 'therefore', suǒyǐ 'so', yīncǐ 'so/for this reason' and yúshì 'thereupon/as a result'. The analysis shows systematic differences regarding the use of connectives in relations that differ in terms of subjectivity, demonstrating that native speakers make use of subjectivity to encode and decode different types of causal relations in discourse. Moreover, our study evidences that a comprehensive model of subjectivity should include the epistemic dimension of certainty about the subjectivity scale that might be indicated by other linguistic elements. In-depth analyses of the test items revealed that the presence/ absence of modality words in the result segments are related to different preferential patterns for the connectives. There is a trade-off between the epistemic dimension of certainty and the expression of subjectivity in the four connectives involved.
\end{abstract}

Keywords: causality; connectives; crowdsourcing; modality words; subjectivity

\footnotetext{
*Corresponding author: Hongling Xiao, Faculty of Foreign Languages and Cultures, Xiamen University, Xiamen, China; and Centre for Language Studies, Radboud Universiteit Nijmegen, Nijmegen, The Netherlands, E-mail: hongling.xiao@ru.nl

Roeland W. N. M. van Hout and Wilbert P. M. S. Spooren, Centre for Language Studies, Radboud Universiteit Nijmegen, Nijmegen, The Netherlands, E-mail: r.vanhout@let.ru.nl (R.W.N.M.van Hout), wilbert.spooren@ru.nl (W.P.M.S. Spooren)

Ted J. M. Sanders, Utrecht Institute of Linguistics, Universiteit Utrecht, Utrecht, The Netherlands, E-mail: t.j.m.sanders@uu.nl
} 


\section{Introduction}

Recent empirical studies using corpus data have shown that the semanticpragmatic distinctions between causal connectives, like therefore and as a result, and causal coherence relations, like Argument-Claim and Cause-Consequence, can be accounted for in terms of subjectivity. More specifically, the meaning and use of causal connectives have been found to relate systematically to the subjectivity features of a causal construction, which provides insight into how subjectivity and causality, as two cognitive principles, function in the characterization of causal connectives and coherence relations in naturalistic discourse (see, e.g., Andersson 2019; Degand and Pander Maat 2003; Li et al. 2013; Pander Maat and Sanders 2001; Sanders and Spooren 2015; Xiao et al. 2021a, 2021b).

The primary aim of this article is to further test the cognitive claims of this subjectivity account: causal coherence relations and connectives are argued to differ from each other, depending on the degree of speaker involvement and perspective in the construal of the causal relation (Pander Maat and Degand 2001; Pander Maat and Sanders 2001). Whereas previous studies on the subjectivity account of connectives and coherence relations mainly focused on western languages (Dutch, French, English, German), the current study focuses on Mandarin Chinese, a language that is typologically very different from the languages for which the theoretical framework was originally developed. If the account can be applied to a typologically completely different language like Mandarin Chinese, this provides evidence for the cognitive plausibility of the subjectivity account (Li et al. 2013).

The central notion of the subjectivity account is 'subject of consciousness' (SoC), "an animate subject, a person, whose intentionality is conceptualized as the ultimate source of the causal event" (Pander Maat and Sanders 2000: 64). The notion of SoC finds its roots in the view that subjectivity in natural languages manifests itself in "the locutionary agent's expression of himself and of his attitudes and beliefs" (Lyons 1982: 102). Language is used subjectively if it expresses "the speaker's subjective belief or attitude toward the proposition" (Traugott 1989: 35) or the "speaker attitude or viewpoint" (Traugott 2010: 30).

Examples (1)-(4) show differences in the way the causal connection between the two discourse segments is construed. In example (1), the causal connection is expressed as an objective link; it can be paraphrased as "the fact that it hasn't rained for a long time causes the fact that the plants have turned yellowish". In terms of Sweetser (1990), it would be classified as a content relation; in the Rhetorical Structure Theory framework (Mann and Thompson 1988) it would be labeled as a non-volitional cause relation. In example (2), the causal link is 
presented as coming from an SoC, which in this case is the speaker: on the basis of the observation that the plants have turned yellowish, the speaker concludes that it must be the case that it hasn't rained for a long time. This is an epistemic relation (Sweetser 1990). Example (3) is another example in which the SoC is the speaker: the situation that the plants have turned yellowish leads the speaker to order the arrangement of a watering cart (a speech act relation, in terms of Sweetser 1990). In example (4), the SoC is a 3rd person character: the drought leads the city council to arrange a watering cart. In Sweetser's terms, this again would be a content relation; in RST it would be a volitional cause.

(1) $[P]$ It hasn't rained for a long time, so [Q] the plants have turned yellowish.

(2) [P] The plants have turned yellowish, so [Q] it must be that it hasn't rained for a long time.

(3) $[P]$ The plants have turned yellowish, so [Q] please arrange a watering cart tomorrow.

$[P]$ It hasn't rained for a long time, so [Q] the city council arranged a watering cart to water the plants.

These causal links show different degrees of subjectivity. Example (1) is most objective as its interpretation does not rely on the presence of an SoC. Example (4) shows a higher degree of subjectivity, as the causal link crucially depends on the presence of an SoC, but that $\mathrm{SoC}$ is a 3rd person, a character in the story world (in this case "the city council"). Examples (2) and (3) are most subjective as there is a 1st person SoC, the speaker (Sanders et al. 2009).

Another aspect of subjectivity concerns the way the SoC is linguistically referred to in the utterance. This is in line with the Langackerian view of subjectivity with regard to the implicit or explicit construal of an entity (Langacker 1990: 7-9). More specifically, the causal construal is objectified when the SoC, in the act of reasoning, is put on-stage, i.e., explicitly referred to in the utterance (e.g., [4]), and subjectified when left off-stage, i.e., remaining linguistically implicit (e.g., [2] and [3]).

A cognitive account which integrates these two aspects - subjectivity of the relation and its linguistic expression - as described by Sanders and Spooren (2015) has been shown to account for the cross-linguistic categorization of causal connectives. Most languages that we are familiar with have more than one causal connective. This implies that language users, in verbalizing their causal content, have to choose one connective over another, or leave the causal connection implicit (see Spooren (1997) and Hoek (2018) for discussions of so-called 
underspecified coherence relations). In actual language use, speakers do not randomly choose a connective from the causal lexicon, but show systematic preferences. There seems to be a close connection between the form and meaning of connectives and people's cognitive construal of relation categories (e.g., Keller 1995; Knott and Dale 1994; Knott and Sanders 1998; Sanders et al. 1992, 1993; Sweetser 1990). For example, in a language like Dutch, the causal connective want 'for' has a preference for signaling epistemic and speech act relations, whereas omdat 'because' is preferred for content relations. Systematic corpus studies of different languages have shown that the meaning and use of causal connectives correlate with the subjectivity profiles of coherence relations that they express, and that causal connectives have a prototype structure revealing that connectives specialize in expressing different degrees of subjectivity (for work on Dutch, French, German and Mandarin Chinese, see, among others, Degand and Pander Maat 2003; Pander Maat and Degand 2001; Pander Maat and Sanders 2001; Sanders and Spooren 2015; Spooren et al. 2010; Stukker and Sanders 2012; Xiao et al. 2021a, 2021b; Zufferey 2012).

Take, for example, the forward causal connectives daardoor and dus in Dutch (Pander Maat and Sanders 2001), de ce fait and donc in French (Pander Maat and Degand 2001), and yúshì and kějiàn in Mandarin Chinese (Li et al. 2013), all roughly meaning 'so'. In each of these languages, the first connective typically expresses objective relations whereas the second typically expresses subjective relations, embodying the two extremes of the objectivity-subjectivity continuum.

The coherence relation in (1), repeated here as ( $\left.1^{\prime}\right)$, has a clear objective profile, representing a cause-consequence relation between two factual events, involving no SoC (non-volitional content). As a result, an objective causal connective fits best. The relation in (2), repeated as ( $\left.2^{\prime}\right)$ below, represents the most subjective construal: the speaker, who remains implicit, reasons toward a personal conclusion that "it hasn't rained for a long time", while taking the P segment "the plants have turned yellowish" as an argument. It accords best with a subjective connective. The coherence relation in example (4), repeated as (4') below, is inbetween objective and subjective: it expresses a volitional content domain relation, having an explicit 3rd person character SoC ("the city council") to take the intentional action "arranged a watering cart [...]" under the circumstances that "it hasn't rained for a long time”. Such structures form the prototypical context for a specific result marker (daarom, c'est pourquoi, yúshì) in each of the three languages mentioned above.

(1') [P] It hasn't rained for a long time, daardoor/de ce fait/yúshì $[Q]$ the plants have turned yellowish. 
[P] The plants have turned yellowish, dus/donc/kějiàn [Q] it must be that it hasn't rained for a long time.

(4') [P] It hasn't rained for a long time, daarom /c'est pourquoi /yúshì $[Q]$ the city council arranged a watering cart to water the plants.

The subjectivity-objectivity division in the meaning and use of causal connectives is not always clear cut; rather it has a prototype nature (Sanders and Spooren 2013; Stukker and Sanders 2012). That is, in actual language data we find cases where a connective with a specific subjectivity profile is used in a context that deviates in one or more aspects from the prototypical subjective environment. In most of these cases there seems to be a clear rhetorical motivation for the deviating pattern (Sanders and Spooren 2013; see also Xiao 2020: Ch. 5 for a discussion of such deviations from prototypicality in Mandarin Chinese). For example, daarom in ( $\left.4^{\prime}\right)$ is also occasionally used to express epistemic relations, and $d u s$ in ( 2 '), to express volitional relations. However, close analyses show that volitional relations expressed by dus more often present the scene from the perspective of the firstperson SoC than volitional relations expressed by daarom. That is to say, volitional relations marked by dus tend to be construed from a more subjective perspective than their daarom counterparts (Stukker and Sanders 2009, 2012). Similarly, omdat 'because' in Dutch and youyu 'because' in Mandarin, both semantically objective, are found to mark epistemic or speech act relations occasionally. Observing the broader context in which these relations occur, Sanders and Spooren (2013) and Xiao (2020: 146-152) observe that these seemingly counterexample usages for the subjectivity account have an objectifying effect on the interpretation of the causal relation: it is the general circumstances that lead necessarily to the conclusion, rather than the SoC's personal reasoning. Such rhetorical effects coming along with the prototypical subjectivity profile of a connective are especially interesting because they support the idea that subjectivity is an inherent property of the connectives under study.

At present, the integrated subjectivity account is largely based on manual analyses of relatively small corpora from a relatively limited set of language, where the analyses were carried out by discourse specialists. This type of evidence limits claims about the generalizability of connectives' categorization across languages and about the cognitive status of the subjectivity account (Sanders and Spooren 2013, 2015; Stukker and Sanders 2012, etc.). More specifically, recent studies have argued that an account which focuses on connectives only is likely to underestimate linguistic indicators of subjectivity, because these may be present at other linguistic levels in discourse than at the level of the connective. For instance, differences between Spanish causal connectives do not seem to correspond 
systematically to differences in subjectivity (Santana et al. 2017, 2018, 2021). However, subjective markers like modal verbs present in one of the discourse segments seemed to a play a role, too. For example, a study of Catalan oral texts found that adding a modal marker to connectives (e.g., perque clar 'because obviously' or es que 'it is just that') helps to express the epistemic nature of the causal relations, or to introduce the speaker's stance towards the causal interpretation (Cuenca 2013). Similarly, a systematic corpus study of Mandarin Chinese found distinctive collocational patterns for suǒy̌ versus kějiàn (Wei et al. 2020). More precisely, modal verbs expressing epistemic stance, such as kěnéng 'may' and yinggāi 'should', were more often the collocates of suǒy̌̆, whereas attitudinal stance markers, such as expressions of surprise like jìngrán 'surprisingly' were identified as collocates of kějiàn.

Because of findings like these, we will investigate how well the subjectivity account fits the distributional patterns of causal connectives, while bearing in mind that subjectivity may be expressed at other levels than that of the connective, such as modal verbs in one of the discourse segments.

Furthermore, we have to be careful not to reject a subjectivity account too soon. For instance, English seems to have a relatively poor lexicon of causal connectives in terms of subjectivity distinctions. The most frequently used connectives are so and because, which are the preferred choice for all types of causal relations. However, Sweetser (1990) and Meier (2002) have already shown that the connective since is more specific and is mainly restricted to epistemic and speech act readings. A recent empirical study on forward causal connectives in English has revealed even more nuanced distinctions. Andersson and Sundberg (2021) argue that there are specific English connectives that can function as cues for subjective and objective causality: therefore and as a result are found to be used systematically across writing and speech for epistemic relations and nonvolitional relations, respectively. And even so, though multifunctional, also exhibits a tendency to occur in subjective contexts. In short, there is evidence that English also follows the subjectivity account of the distinctions between the forward causal connectives, though not as clearly as other European languages such as Dutch, French, and German.

Such considerations show that there is a need to test the subjectivity account in other languages. There is also a need to use different types of data to test the subjectivity account, over and above the intuitions of discourse specialists. If the subjectivity account wants to claim cognitive plausibility, the distinctions made by the account should also show up in the language behavior of language users who are not trained as discourse specialists.

In this study, we take Mandarin Chinese as a case to further substantiate the subjectivity claim. We use a connective insertion task to tap native speakers' 
intuitions about causal coherence. This insertion task was performed on a crowdsourcing platform and as such provides a method which is complementary to corpus analysis, and which can provide interesting information about the construal of language and discourse by linguistically untrained language users. This task has not previously been used in the study of Mandarin connectives. We intend to test the distinctions between objective and subjective causal connectives and coherence relations that follow from the basic model of subjectivity which has its basis in corpus studies.

\section{A subjectivity analysis of Mandarin result connectives}

In this study we focus on four result connectives ${ }^{1}$ kějiàn 'therefore', suǒyǐ 'so', yīncǐ 'so/for this reason' and yúshì 'thereupon/as a result' in Mandarin Chinese. Though semantically similar as causality markers in discourse, fundamental distinctions have first been observed with regard to the type of causal events each typically expresses.

Kějiàn is composed of two lexical words, kě 'may/can' and jiàn 'see'. It has gone through a grammaticalization process from a phrasal verb to a discourse connective (literally, 'it can be seen that') that specializes in conveying personal attitudes, comments and judgments (Li 2012). In other words, it expresses inferential causality (Lü 1999: 335; Xing 2001: 40-41).

Yúshì is characteristic of introducing a dynamic and narrative $Q$ that indicates an action or a change of state triggered by the situation in P (Guo 2006; Lü 1999: 636; Xing 2001: 527).

Recent studies have described the differences between these two connectives in terms of subjectivity: kějiàn is a specific connective marking epistemic domain causality, whereas yúshì marks content domain causality (Li et al. 2013; Xiao et al. 2021b). Moreover, kějiàn typically occurs with implicit speaker perspective, whereas yúshì typically occurs in a context with an explicit character perspective. A typical causality instance using kějiàn is in example (5) below. ${ }^{2}$ The characterizing uses of yúshì in

1 We choose to the use the term "result connectives" over "forward causal connective" as used in the literature studying English and other European languages, because in Mandarin discourse, the terms "backward" and "forward" do not help much to differentiate between the cause and the result relations. The cause relations expressed by youyu 'because' and jiran 'since', for example, are most often in forward structures, as are the result relations.

2 All the Mandarin examples were extracted from the sub-corpus of newspaper texts of LDC95T13 (Wu 1995). 
content domain are illustrated in example (6), a volitional content relation perceived by an explicit character-SoC, and (7), a non-volitional content relation.

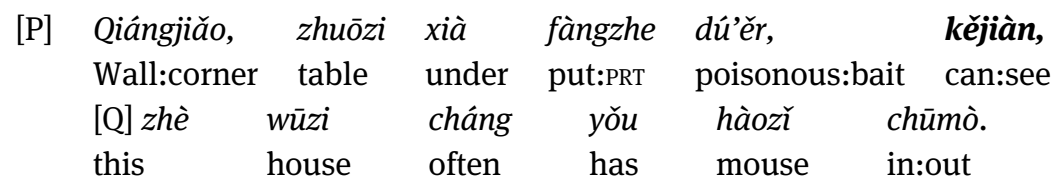

[P] 'There are poison baits in the corners and under the table,' kějiàn 'therefore' $[\mathrm{Q}]$ 'there are often mice in this house.'

$\begin{array}{llllll}\text { [P] Zǒngcái } & \text { gēnjù } & \text { duì gāngtiě } & \text { shichăng } & \text { de } \\ \text { President } & \text { according } & \text { PREP steel:iron } & \text { market } & \text { ATTR } \\ \text { yùcè, } & \text { rènwéi guò } & \text { jǐnián } & \text { hòu } & \text { gāngtiě } & \text { jiàgé } \\ \text { prediction, } & \text { believe after } & \text { few:year later } & \text { steel:iron } & \text { price }\end{array}$
yīdìng huì shàngzhăng, yúshì, $[Q]$ tā gòuzhìle certainly MOD up:rise CONN 3sG purchase:ASP dàliàng liánjià shèbèi, guǒduàn shàngmă. big:amount cheap:price equipment decisive on:board

[P] 'According to the prediction for the steel market, the president believed that steel prices would certainly rise in a few years,' yúshì 'thereupon' [Q] 'he purchased a lot of cheap facilities to start decisively.'

[P] Suízhe zhīshí xìnxī rìỳ zèngduō, dān kào PREP knowledge information day add:more only rely “dătīng” xiănrán yìjing búgòu. Yúshì [Q] ask obviously already NEG:enough ConN shèjídào gèhánggèyè de zhuānyè zĩxún involve:adv every:industry:every:field ATTR profession consult gōngsī biàn yìngyùn'érshēng. company then follow:situation:ADv:appear.

[P] 'With knowledge and information increasing every day, it is obviously not enough anymore to simply rely on "asking around".' Yúshì 'As a result' $[\mathrm{Q}]$ 'professional consulting companies serving all kinds of industries came into being.'

Suǒyǐ and yincǐ are both less specialized and frequently used in a variety of contexts. They are multi-functional in expressing different types of causal relations, be it expositive, narrative, or inferential and argumentative (or, in Sweetser's (1990) terms, content or epistemic) (Guo 2006; Li et al. 2013; Zhao 2003). Yet compared to suǒyĭ, yincǐ is found to disprefer the subjective category speaker as the SoC or 
concluder, and displays a tendency toward expressing non-volitional relations (Xiao et al. 2021b).

In many cognitive linguistic studies, findings and conclusions have been obtained through corpus-based studies or qualitative analysis, which were conducted under a predefined theoretical framework. The annotation and feature analysis of the causality structures are made by a limited number of expert researchers or trained annotators. This certainly guarantees the quality of the annotation, which adds to the validity and reliability of the conclusions drawn from these studies. Nevertheless, the annotating process is subject to potential biases, for example, the framework bias (Riezler 2014; Scholman and Demberg 2017a) and the individual bias (Artstein and Poesio 2005, 2008) (see Section 3.1).

What is needed to investigate the cognitive reality of such analyses is a test that the distinctions made in the analyses are also made by native speakers who are not trained as discourse analysts. The current study aims to fill this gap by conducting a crowdsourcing experiment to see whether each connective's subjectivity profile is reflected in the interpretations that untrained, non-expert informants make of a causal event. The data recruited can serve as a complement to existing corpus studies and further test the theoretical model of integrated subjectivity.

In the crowdsourcing experiment, participants were asked to select a best-fit connective to express a causal relation, which is unambiguously subjective or objective in terms of the features well-defined in the existing subjectivity model (see Section 3.2.1). We expect the main findings from the corpus studies to be reflected in the crowdsourcing experiment. Our hypotheses about participants' choices between the connectives in our experiment are as follows:

1) kějiàn will be chosen to express predominantly causal relations with a subjective profile;

2) yúshì will be chosen to express predominantly causal relations with an objective profile;

3) suǒy̌ and yīncǐ will be chosen in both profiles, yet

4) compared to suǒy̌̌, yīnč̌ will be chosen relatively more often in the objective profile.

\section{Methodology}

\subsection{Crowdsourcing experimentation and discourse annotation}

Crowdsourcing, as it is called, is the act of engaging the "crowd", a nonspecific public group, to accomplish a task which was once designated to just a specialized 
few (cf. Crowdsourcing n.d.; Howe 2008). It is a sourcing model originally used in industry, but now also commonly used in academia. In various research fields, among which natural language studies, the crowdsourced data have proven to be at least as reliable as the data by experts. For example, Zaidan and Callison-Burch (2011) obtained near professional-quality translation (as by professional translation agencies) for an Urdu-to-English translation task by non-professional translators using Amazon Mechanical Turk (MTurk). In natural language annotation tasks for word similarity, recognizing textual entailment, word sense disambiguation and the like, non-expert annotations collected with MTurk all showed high agreement with existing gold standard labels provided by expert annotators (Snow et al. 2008).

More recently, the crowdsourcing approach has gained attention in discourse annotation studies. First of all, in a connective insertion task, the reliability of the crowdsourcing method for annotating discourse coherence relations was tested and proved (Scholman and Demberg 2017a). In this study, six types of annotated discourse relations from both the Penn Discourse Treebank (PDTB, Prasad et al. 2008) and the Rhetorical Structure Theory Discourse Treebank (RST-DT, Carlson et al. 2003) were assigned to participants recruited with Prolific Academic (a crowdsourcing platform alternative to MTurk, tailored for academic research). They were asked to indicate their interpretation of the relations by inserting a connective from a list of candidate connectives. The results are consistent with the expert annotations available in the two corpora. Another study reports a rapid and successful development of a Japanese corpus with discourse annotations using a two-stage crowdsourcing approach: (i) first determine the existence of a discourse relation between a clause pair of segments and (ii) then label it (Kawahara et al. 2014). Also, through crowdsourcing experimentation, it was found that a conjunction, and sometimes more than one valid connection between discourse units, can often be inferred alongside an explicit discourse adverbial (Rohde et al. 2015, 2016). Another finding is that examples and specifications in discourse can have both elaborative and argumentative interpretations for readers. In other words, conjunctions not only function to illustrate/specify a situation but also to provide an argument for a claim (Scholman and Demberg 2017b). Another relevant finding is that the Spanish causal connective puesto que 'given that' is preferred more than porque 'because' when native speakers express subjective relations in discourse (Santana et al. 2021).

Crowdsourcing discourse annotations has many advantages. First, it is commonly recognized as an efficient and economical way to collect large amounts of data, as well as a large number of respondents, since untrained participants are more "widely available" (Krippendorff 2004). This subsequently helps to decrease considerably the individual bias generated in annotation tasks that are usually 
performed when only a limited set of annotators is used (Artstein and Poesio 2005, 2008). Moreover, the non-expert background of participants prevents them from performing under influence of implicit or tacit expert knowledge (Riezler 2014) and helps them to base their judgments on the intuition and knowledge developed in the actual use of language as a native speaker.

In addition, in the current study, by conducting the connective insertion task, the so-called framework bias can be avoided since participants do not need to follow a specific codebook as in traditional annotation tasks (Riezler 2014; Scholman and Demberg 2017a). The findings, therefore, provide insights into the subjectivity of Mandarin result connectives from the perspective of untrained native speakers. Such data thus contribute to and complement our understanding gained from corpus-based studies, in which the annotation is conducted by a limited number of expert or trained annotators following a defined theoretical framework.

\subsection{A case study of Mandarin result connectives}

The current experiment was hosted by LingoTurk, which is "an open-source, freely available crowdsourcing client/server system aimed primarily at psycholinguistic experimentation" and "enables user-friendly local hosting of experiments as well as condition management and participant exclusion” (Pusse et al. 2016: 57). We have made use of an existing paradigm (Santana et al. 2021; Scholman and Demberg 2017a, 2017b).

\subsubsection{Materials and experimental design}

The materials used in the experiment consisted of two parts: experimental relations (causal) and filler relations (concessive and instantiation). All were extracted from the sub-corpus of newspaper texts of LDC95T13 (Wu 1995). We have confined our material selection to feature articles to have consistency in writing style. Using only newspaper texts was deemed sufficient as the register for material extraction because it guarantees that participants are not influenced by style variations, and we know from other studies that the fundamental subjectivity profile of a Mandarin causal connective does not vary with register variation (Xiao et al. 2021a, 2021b). Therefore, the results are generalizable to other registers.

To investigate whether the subjectivity profile of a causal relation has a significant influence on participants' choice of connectives, we created two conditions: subjective and objective, namely, the argument-claim relations (epistemic domain) and the cause-consequence relations (content domain). We selected 
experimental items that are as unambiguous as possible with respect to the three aspects that are crucial to defining the subjectivity profile of a causal relation. To be precise, for the subjective condition, we used relations that encode a maximum degree of subjectivity: a claim/conclusion as the consequent $(Q)$, from the perspective of the speaker SoC, who remains implicit (epistemic relation). Relations in the objective condition encode the maximum degree of objectivity: they express a factual $Q$ in that there is no involvement of an SoC (non-volitional content relation) or an act that is performed intentionally by a 3rd person character $\mathrm{SoC}$, who is explicitly referred to in the utterance (volitional content relation).

Sometimes it was necessary to simplify the fragments for experimental purposes (e.g., deleting some attributive or adverbial phrases), but care was taken that this did not affect the naturalness of the phrasing, or the appropriateness of the original connective in the context. The goal of the adaption was to help participants focus on the judgment task while not being distracted by specific writing styles.

This procedure resulted in selecting 24 subjective causal relations (originally marked with kějiàn, suǒy̌ and yīnč̌, eight for each connective) and 24 objective causal relations (originally marked with suǒy̌̀, yinnč̌ and yúshì, also eight for each). Those originally marked with kějiàn and yúshì occur only in one condition because the former is highly specialized in expressing subjective relations and the latter in expressing objective relations (Li et al. 2013; Xiao et al. 2021b). The 48 test items were equally divided over two lists, each containing twelve subjective items (four of kějiàn, suǒy̌ and yīnč̌ each) and twelve objective items (four of suǒy̌̆, yīnč̌ and yúshì each).

In addition, we selected 16 filler items: eight concessive relations marked with dànshì 'but' and eight instantiation relations marked with b̌rú 'for example'. Dànshì and b̌̌rú are the most typical markers expressing respectively concessive and instantiation relations, and they stand out quite clearly from the test connectives in the sense of semantics as well. These 16 filler items were placed randomly in both lists, resulting in two 40-item lists (24 test items and 16 filler items) in the end.

To facilitate interpretation of the coherence relations, one context sentence $\left(C_{1} / C_{2}\right)$ was provided before and after the two segments that are linked to each other, i.e., the antecedent $P$ and the consequent $Q$. Thus, each item takes the form of $C_{1}+P / /$ potential connective $/ / Q+C_{2}$. While displaying each item, the two context sentences were greyed out and the two segments were in black font. In doing so, participants could focus on the task of choosing a connective, while at the same time using the contextual information for a precise judgment and interpretation. Before and after the potential connective, punctuation marks that were present in the original were removed and double slashes (//) were added so 
as to avoid a possible influence of punctuation marks on the participants' choice of a particular connective. We also paid attention that none of the candidate connectives, or their synonyms such as rán'ér versus dànshì, both meaning "but/ however", appeared anywhere in the experimental items. All original connectives were stripped from the fragments.

Examples (8), (9) and (10) $)^{3}$ are examples of experimental items, which illustrate respectively the subjective condition (conclusion $Q$, implicit speaker $S o C$ ), the objective condition with physical act $Q$ and explicit character SoC (he, the president), and another objective condition with a factual $Q$ involving no SoC.

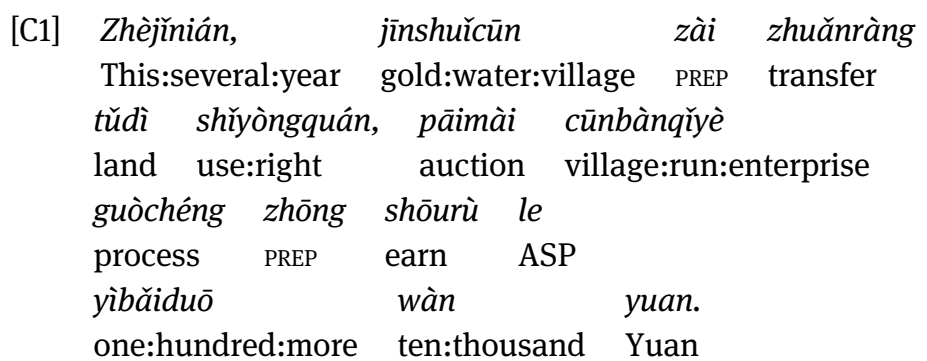

'In the past few years, Village Jinshuǐ has earned more than one million yuan in the process of transferring rights of land use and auctioning village-running enterprises.'

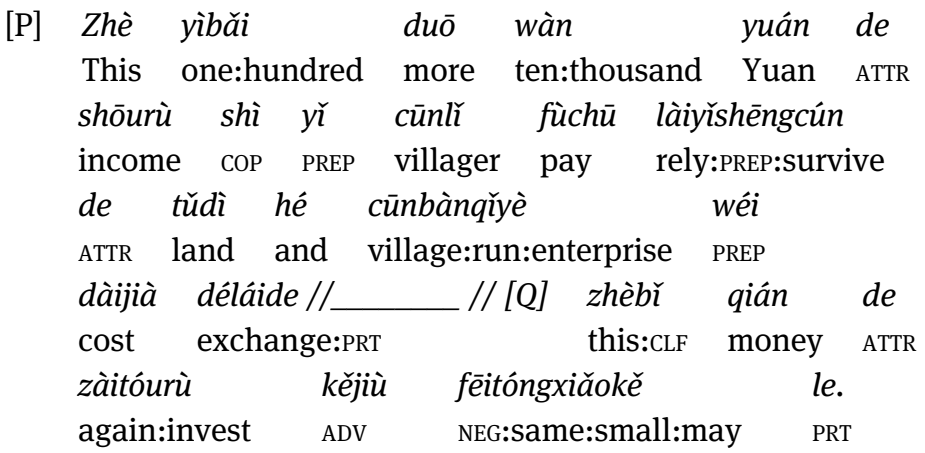

'This income of more than 1 million yuan was obtained at the expense of the land and village enterprises that the village relied on'

$/ /[/[\mathrm{Q}]$ 'the reinvestment of this money is simply not a small issue.'

3 The interlinear glossing for the causal structure part in examples (9) and (10) is left out here since it has been provided in examples (6) and (7), respectively, in Section 2. 
[C2] Àn

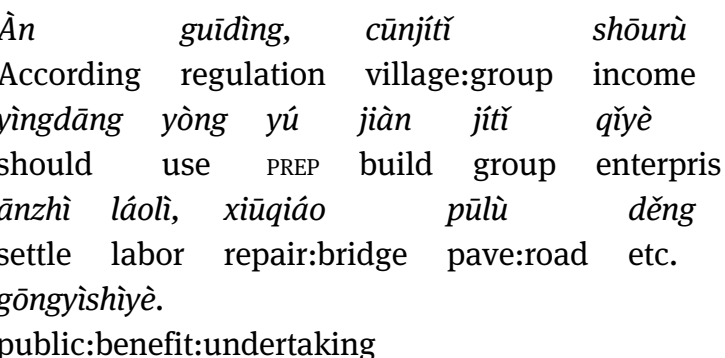

'According to the regulations, the collective income of the village should be used for the construction of collective enterprises to resettle labor, for repairing bridges, paving roads and other public welfare undertakings.'

[C1] Gōngsī zài dàguimó jiànshèshí, zhèng Company PREP big:scale construction:time ASP zhí shìjiè gāngtiě shēngchăn de dīgǔ. PREP world steel:iron production ATTR low:valley 'The company was under large-scale construction when the world's steel production was right at the bottom status.'

[P] Zǒngcái gēnjù duì gāngtiě shìchăng de yùcè, rènwéi guò jǐ nián hòu gāngtiě jiàgé yĩdìng huì shàngzhăng // // [Q] tā juédìng gòuzhì dàliàng liánjià shèbèi, guǒduàn shàngmă.

'According to the prediction for the steel market, the president believed that steel prices would rise in a few years' // $/ /[\mathrm{Q}]$ 'he decided to purchase a lot of cheap facilities to start decisively.'

[C2] Shìshí zhèngmíng dāngshí de Reality prove that:time ATTR yùcè shì wánquán zhèngquède. prediction COP complete correct:PRT 'As it turned out that the predictions at the time were completely correct.'

[C1] Dāngīin shèhuì fēngōng yuè lái yuè xì, Nowadays society divide:la more:ADv:more:detailed "géháng rú géshān". separate:field like separate:mountain 'Social division of labor is getting more and more fine-grained nowadays, "different trades being separated as by mountains.", 
[P] Suízhe zhīshì, xìnxī rìyi zēngduō, dān kào "dătīng” xiănrán y̌̌jīng bùgòu //__ // [Q] shèjì dào gèhánggèyè de zhuānyè zīxún gōngsĩ biàn yìngyùnérshēng.

'With knowledge and information increasing every day, it is obviously not enough anymore to rely on "asking around" alone' $/ /[/ /[\mathrm{Q}]$ 'professional consulting companies serving all kinds of industries came into being.'

$\begin{array}{llll}\text { [C2] Zīxún } & \text { gōngsī } & \text { zhújiàn } & \text { chéngwéi } \\ \text { Consult } & \text { company } & \text { gradually } & \text { become } \\ \text { běijī } & \text { de } & \text { rèmén } & \text { hángdang. } \\ \text { Beijing } & \text { ATTR } & \text { hot:door } & \text { business } \\ \text { 'Consulting } & \text { gradually became a popular business in Beijing.' }\end{array}$

\subsubsection{Participants}

A total of 151 native Chinese speakers (52 males; 98 females; 1 without gender indication) participated in the experiment. They were recruited from two university-based WeChat ${ }^{4}$ groups in the Netherlands: Radboud University and Leiden University. Both universities cover a wide variety of educations, so we can tap from a highly diverse participant reservoir. Each participant was assigned a unique ID and was paid 4 euros. Participants were randomly attributed to one of the two lists. Seventy participants ( 41 from Nijmegen, 29 from Leiden) completed list 1, 81 participants ( 46 from Nijmegen, 35 from Leiden) completed list 2 . The age of the participants ranges from 19 to 38, and their education level ranges from undergraduate to doctoral degrees. None of them reported growing up in a bilingual background (Chinese and a foreign language) or any reading disorder.

\subsubsection{Procedure}

The two lists of items were published via two separate URLs and were completed by participants individually. The presentation order of the items in each batch was randomized to avoid order effects. Researchers could keep track of the experiment progress through two other URLs. The experiment conforms completely to the standard experimental research into linguistic judgement of language fragments

4 WeChat (Wèixìn) is a Chinese messaging and social media app. 
defined by the Ethics Assessment Committee Humanities (EACH) of Radboud University (https://www.ru.nl/eac-humanities/).

On the first page, participants were presented with the introduction to the study. Next, they were presented with the consent form and informed that they could quit the experiment at any point without giving any reason. Upon accepting the consent form, they were asked to provide background information on the following page (gender, age, nationality, level of education, whether or not raised in childhood in a bilingual environment [Chinese and a foreign language], and whether they had ever been diagnosed with a reading disorder). Then they entered the actual experiment (Figure 1 below), which contained short instructions, a box with six candidate connectives, an extra button for manual answers, and a discourse fragment. Participants were asked to read the fragment carefully and then to "drag and drop" in the box the connective that best signals the coherence relation between the two segments in black font, while taking into account the contextual sentences in grey font. Selecting a connective was mandatory in that participants could not proceed without such a choice. However, participants could click on the button dōu búshì 'none of these' and manually type in a connective that is more proper as they see it. In case they changed their mind at this point, they could click on the button fănhuí 'return'. Then they could use the "drag and drop" function again. The average time for completing the task is 00:17:00 for list 1 and 00:16:58 for list 2.

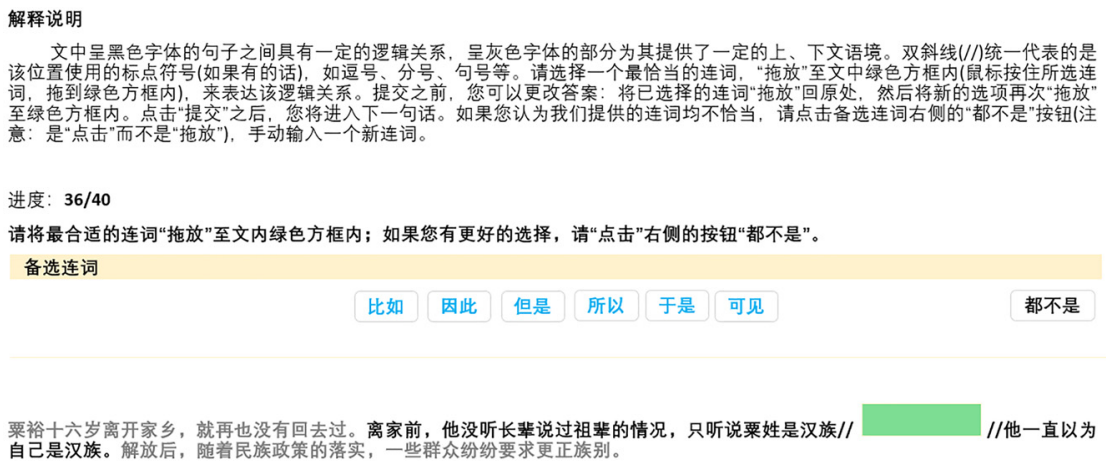
该位置使用的标点符号(如果有的话), 如逗号分号, 句号等。请选择一个最恰当的连词, “拖放”至文中绿色方框内(鼠标按住所选连 词, 拖到绿色方框内), 来表达该逻辑关系。提交之前, 像可以更改答案: 将已选择的连词“拖放”回原处, 然后将新的选项再次“拖放” 至绿色方框内。点击“提交”之后, 您将进入下一句话。如果佖认为我们提供的连词均不恰当, 请点击备选连词右侧的“都不是"按钮注 意: 是“点击"而不是“拖放”), 手动辅入一个新连词。

进度: $36 / 40$

请将最合适的连词“拖放”至文内绿色方框内; 如果您有更好的选择, 请“点击”右侧的按钮“都不是”。 备选连词$$
\text { 比如 因此但是 所以 于是 可见 }
$$

粟裕十六岁离开家乡, 就再也没有回去过。离家前, 他没听长辈说过祖茂的情况, 只听说粟姓是汉族// 自己是汉族。解放后, 随着民族政策的落实, 一些群众纷纷要求更正族别。

Figure 1: Screenshot of the experiment interface on LingoTurk. 


\section{Results}

\subsection{Data cleaning}

We succeeded in collecting data from 151 individual participants. The system registered two different submissions by one single participant, whose background information was also missing. Therefore, both submissions from this participant were excluded. Data by the remaining 150 participants (6,000 observations: 2,800 from list 1, with 70 participants; 3,200 from list 2, with 80 participants) are presented in Figure 2 below. It shows that the distinction between the filler and the experimental items is successful. There is hardly any variation within the two filler categories, whereas all four causal connectives were elicited frequently in the causal relations.

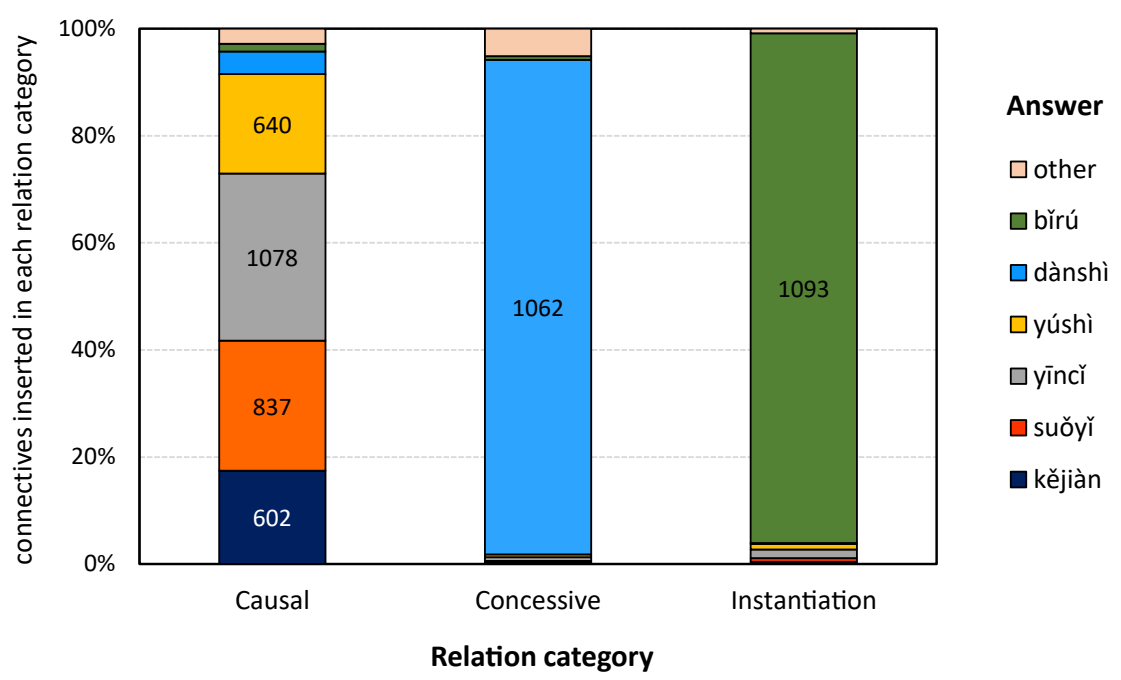

Figure 2: Frequencies and percentages of participants' answers in the test causal relations and two filler categories of concessive and instantiation relations. The answer 'other' refers to the connectives manually typed in by the participants.

To evaluate more precisely the quality of the answers from the 150 participants, we employed a double-check strategy. First, we set $80 \%$ as the baseline of agreement between the semantics of the inserted connectives by participants and the semantics of the original items, i.e., causal, concessive, or instantiation. Eleven participants did not meet this baseline. Second, we checked the manual answers (if any) provided by these eleven participants. It was found that five participants filled in connectives that are synonyms of those expected from the candidate connective list. Most manual 
answers occurred in the concessive relation: participants used rán'ér, kěshì, kě, or dàn in place of dànshi, all meaning 'but/however'; some occurred in the instantiation relation: lìú was used where bǐrú was expected, both meaning 'for example/for instance'. These alternative answers are sensible and fit well in the items. Therefore, the data of these five participants were kept. The other six participants, when providing a manual answer, chose semantically unrelated answers. Their data then were removed from the complete dataset. This left us with 144 participants. One other participant's data were removed because he/she inserted yincǐ for almost all the causal relations: 22 out of 24 (92\%). All in all, the data of 143 participants were maintained.

One test item, a causal relation from list 2 (originally with the connective suǒyz), was deleted because it generated only four observations of causal connectives from the 74 participants in this group. Apparently, the semantics of this item was rather ambiguous, having no causal interpretation for most of the participants.

To sum up, one test item and seven participants' submissions were discarded in the end. This results in 69 participants of group 1 with 24 test items and 16 fillers, and 74 participants in group 2 with 23 test items and 16 fillers. In total we thus have a final dataset of 5,646 observations with 3,358 for test items and 2,288 for fillers.

In Table 1 we show the 3,358 observations for the test items. The choices made by the participants are predominantly the causal connectives kějiàn, suǒy̌̃, yīnč̃ and yúshì (3,153 out of the cleaned-up dataset, 93.9\%). The other 6.1\% were filler connectives b̌rú 'but' and dànshì 'for instance', and "other” (the manually inserted answers by using the "none of these" button). As these choices for non-causal connectives were relatively rare $(6.1 \%$ in total) and did not display any pattern, they were left out from the statistical analyses.

Table 1: Summary of participants' answers for the 47 test items.

\begin{tabular}{|c|c|c|c|c|c|c|c|c|}
\hline \multirow[b]{2}{*}{ Answers } & \multicolumn{4}{|c|}{ Causal connective } & \multicolumn{2}{|c|}{ Filler connective } & \multirow{2}{*}{$\begin{array}{c}\text { Other } \\
\text { Manual }\end{array}$} & \multirow[t]{2}{*}{ Total } \\
\hline & kějiàn & suǒyǐ & yīncǐ & yúshì & bǐrú & dànshì & & \\
\hline Frequency & 602 & 836 & 1,075 & 640 & 51 & 79 & 75 & 3,358 \\
\hline Percentage & $17.9 \%$ & $24.9 \%$ & $32.0 \%$ & $19.1 \%$ & $1.5 \%$ & $2.4 \%$ & $2.2 \%$ & $100 \%$ \\
\hline Total & \multicolumn{5}{|c|}{3,153 (93.9\%) } & 130 & 75 & 3,358 \\
\hline
\end{tabular}

\subsection{Cluster analysis and model selection}

The test items were selected based on their subjectivity profiles (cf. Section 3.2.1), half of them being objective and the other half subjective. If the assumption is correct that the subjective-objective distinction with regard to the three aspects is the sole element influencing participants' decisions, we would expect that the answers given 
by the participants reflect such a binary distinction. In order to check this assumption, we carried out a hierarchical cluster analysis using Ward's method in SPSS 23. The input were frequencies of the four connectives that participants have chosen for each of the 47 experiment items. Interestingly, the dendrogram below (Figure 3) suggests two interpretable distinctions of these items: three clusters and five clusters. In addition, a two-way split does not coincide with the two conditions assumed in the experiment (15 items in the left cluster, the remaining 32 in the right cluster).

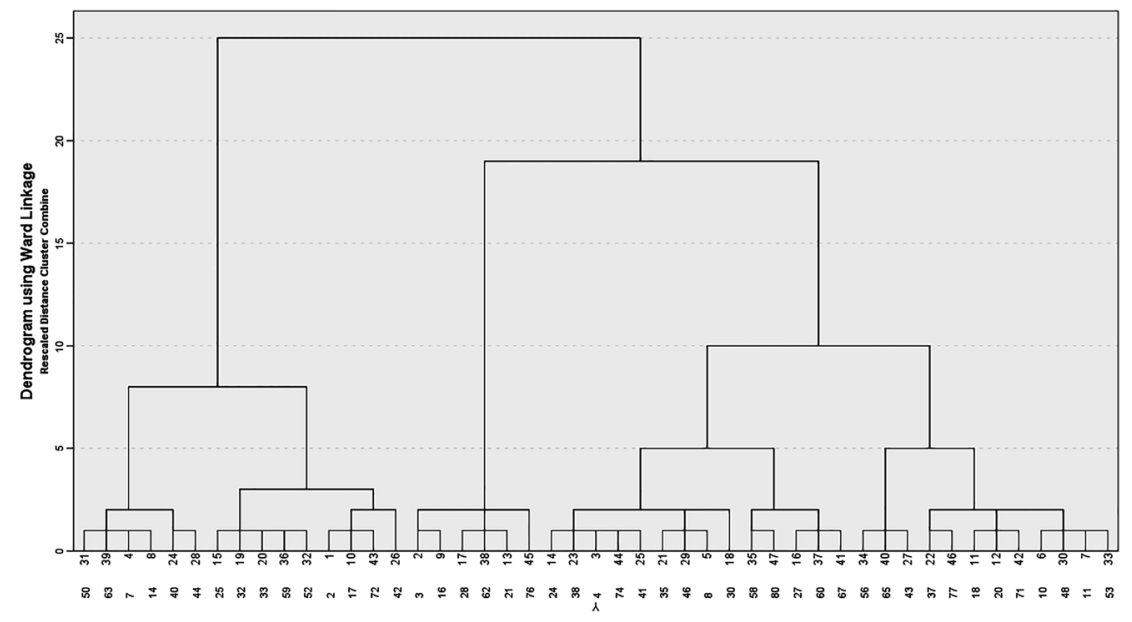

Figure 3: Dendrogram figure produced in the hierarchical cluster analysis defining the clustering of the 47 test causal items (Ward linkage; chi square distances).

To compare the quality of the original condition (subjectivity) and the two solutions suggested by the cluster analysis, we used generalized linear mixedeffects regression with the logit link function and random intercepts for items and participants (package lme4 in R, Baayen et al. 2008; R Core Team 2017). The dependent variable was the participants' choice for a particular connective versus its three alternatives, i.e., kějiàn versus non-kějiàn, yúshì versus non-yúshì, suǒyǐ versus non-suǒy̌̆, and yīnč̌ versus non-yīnč̌. The three models contain as a fixed effect predictor (1) the binary subjective-objective condition, (2) the three-cluster solution, or (3) the five-cluster solution.

Results from all models showed a significant effect of the predictor on distinguishing the connectives (see also the reports in the Appendix). To compare the fits of the three models, we applied the anova function. The results are presented in Table 2. All three indices for each of the four connectives indicate the superiority of the five-cluster solution. AIC, BIC, and the deviance score obviously decrease going from the two-way to the five-way categorization. 
Table 2: Results of anova comparing the fits of 2 condition-, 3 cluster- and 5 cluster-model for predicting the answers of kějiàn, yúshì, suǒyǐ and yīncǐ, with three criteria for model fit (AIC, BIC, deviance).

\begin{tabular}{lrrrrrrrr}
\hline & df & AIC & BIC & logLik & Deviance & Chisq & df & $\operatorname{Pr}(>$ Chisq) \\
\hline kějiàn_2cond. & 4 & $1,446.6$ & $1,470.8$ & -719.30 & $1,438.6$ & & & \\
kějiàn_3clus. & 5 & $1,444.1$ & $1,474.3$ & -717.03 & $1,434.1$ & 4.5378 & 1 & 0.033 \\
kějiàn_5clus. & 7 & $1,408.9$ & $1,451.3$ & -697.45 & $1,394.9$ & 39.1564 & 2 & $<0.001$ \\
yúshì_2cond. & 4 & $1,895.7$ & $1,919.9$ & -943.83 & $1,887.7$ & & & \\
yúshì_3clus. & 5 & $1,868.9$ & $1,899.2$ & -929.43 & $1,858.9$ & 28.796 & 1 & $<0.001$ \\
yúshì_5clus. & 7 & $1,851.1$ & $1,893.5$ & -918.53 & $1,837.1$ & 21.808 & 2 & $<0.001$ \\
suǒyǐ_2cond. & 4 & $3,149.8$ & $3,174.0$ & $-1,570.9$ & $3,141.8$ & & & \\
suǒyĭ_3clus. & 5 & $3,107.6$ & $3,137.8$ & $-1,548.8$ & $3,097.6$ & 44.255 & 1 & $<0.001$ \\
suǒyǐ_5clus. & 7 & $3,091.3$ & $3,133.7$ & $-1,538.7$ & $3,077.3$ & 20.220 & 2 & $<0.001$ \\
yīncǐ_2cond. & 4 & $3,671.7$ & $3,695.9$ & $-1,831.8$ & $3,663.7$ & & & \\
yīncǐ_3clus. & 5 & $3,622.0$ & $3,652.3$ & $-1,806.0$ & $3,612.0$ & 51.681 & 1 & $<0.001$ \\
yīncí_5clus. & 7 & $3,604.4$ & $3,646.8$ & $-1,795.2$ & $3,590.4$ & 21.582 & 2 & $<0.001$ \\
\hline
\end{tabular}

Figure 4 below gives an overview of the distribution of the four connectives over the five clusters. It shows that in cluster 1, participants had a clear preference for yúshì; in cluster 2, yúshì was also preferred, but together with yīncǐ; suǒyì and yincǐ account for the great majority in cluster 4 ; in cluster 5 , kějiàn, suǒyĭ and yīnč were all frequently used; in cluster 3, kějiàn is the predominant choice.

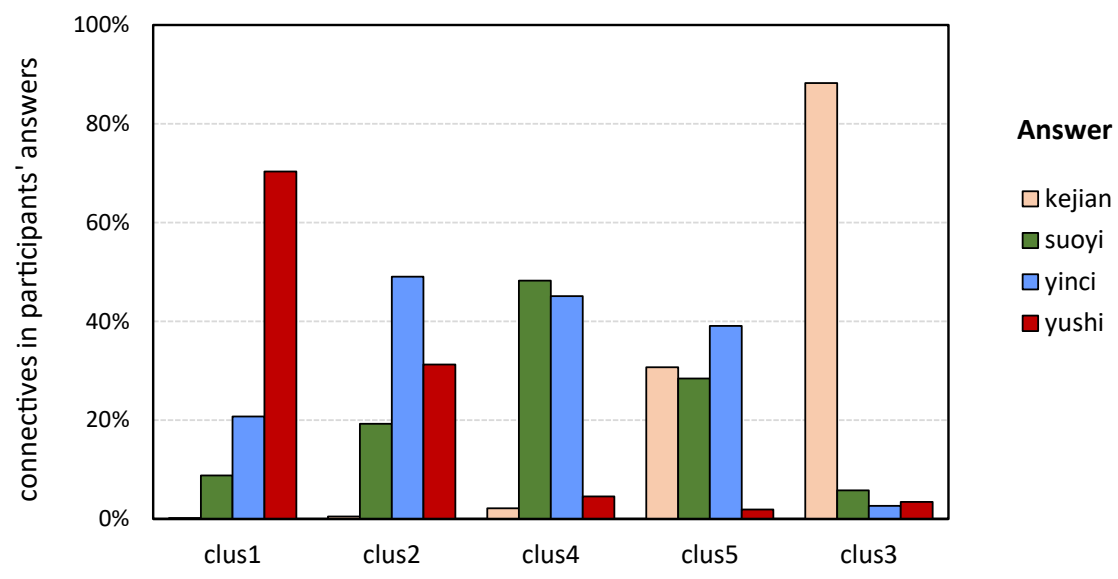

Clustering of participants' answers

Figure 4: Clustering of participants' answers and the percentages of the connectives that participants have chosen in each cluster. 
To sum up, yúshì and kějiàn appear to be clearly different from each other. The former is chosen mainly in clusters 1 and 2, while the latter almost exclusively in clusters 3 and 5. Suǒy̌ and yinnč are more widely used and similar to a large extent, and both stood out clearly in cluster 4. Yet they also differ in that yincǐ has been preferred to suǒyz in both clusters 1 and 2. These observations suggest that the four connectives can be distinguished in terms of subjectivity, as suggested in previous corpus studies: yúshì and kějiàn form a clear contrast; suǒyǐ and yīncǐ are two connectives in-between, the latter being relatively objective compared to the former. Yet the significantly superior model of five-clustering results suggests that other linguistic factors are at work that account for further distinctions between the connectives. This raises the issue what these other factors are, and how they moderate the expression of subjectivity together with the connectives.

\subsection{Interpreting the five-cluster solution}

The five clusters of test items, based on the participants' answers, are presented in Figure 5 below with the relative proportion of the causality categories. To find out the potential factors that contribute to this pattern, an exploratory analysis was made of the test items cluster by cluster. The first factor we investigated in the exploratory analysis was modality, because it is known from the literature that modality may be a confounding factor in explaining the distributional properties of subjective versus objective connectives. And indeed, the five clusters showed an interesting relationship between the presence of modality words and preference for a specific connective.

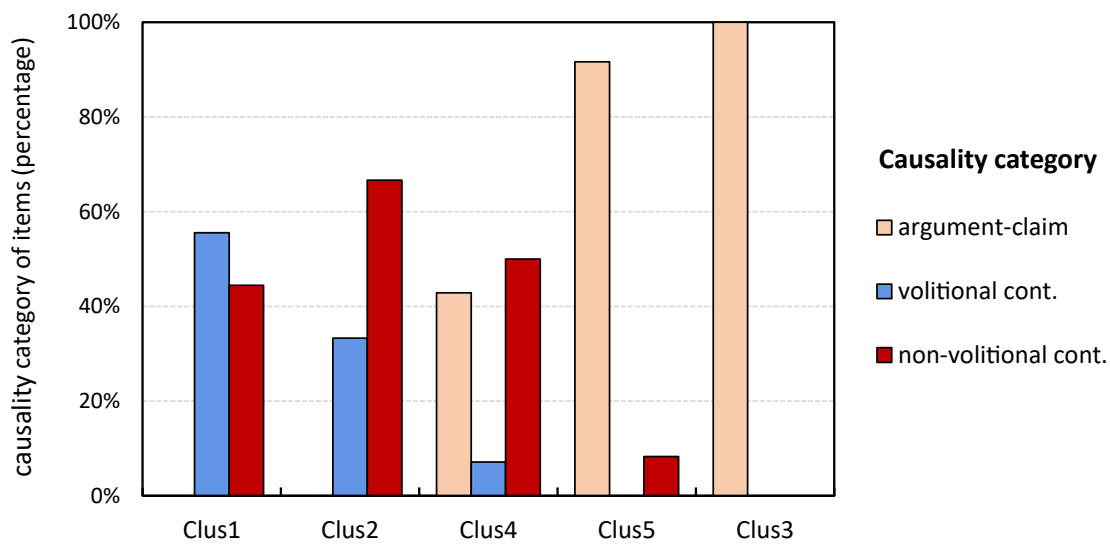

Clustering of experimental items

Figure 5: Clustering of the items and proportion of the causality categories, in terms of subjectivity, in each cluster. Argument-claim relations are items representing the subjective condition; causeconsequence relations, both volitional content and non-volitional content, represent the objective condition. 
First, there are two clusters in which modal words are totally absent. These are clusters 1 and 2, containing only objective relations. Cluster 1 has a strong preference for yúshì, and cluster 2 has a preference for yúshì and yīncǐ. The modality words that occur in cluster 3, which contains only subjective relations, and with a strong preference for kějiàn, express a high degree of certainty about the result, such as zhàoyàng 'exactly the same/without exception' and jiùshì 'definitely/ surely'. The modality words occurring in clusters 4 and 5 are hedging words, such as yīnggāi/kěy̌̃ 'should/might', xiăndé 'seem to be', and duōshăo 'more or less'. Cluster 4 contains both objective and subjective relations, and the preferred connectives are suǒy̌ and yinnč. Cluster 5 contains mostly subjective relations, but has a very diverse connective preference.

To get a better understanding, we carried out a correspondence analysis on the answer frequencies of the four connectives per item using the R package FactotoMineR (Le et al. 2008). The result was that two dimensions are sufficient to explain $93.7 \%$ of the total variation contained in the data. The relationship between items and connectives can be visualized in a two-dimensional bi-plot, cf. Figure 6.

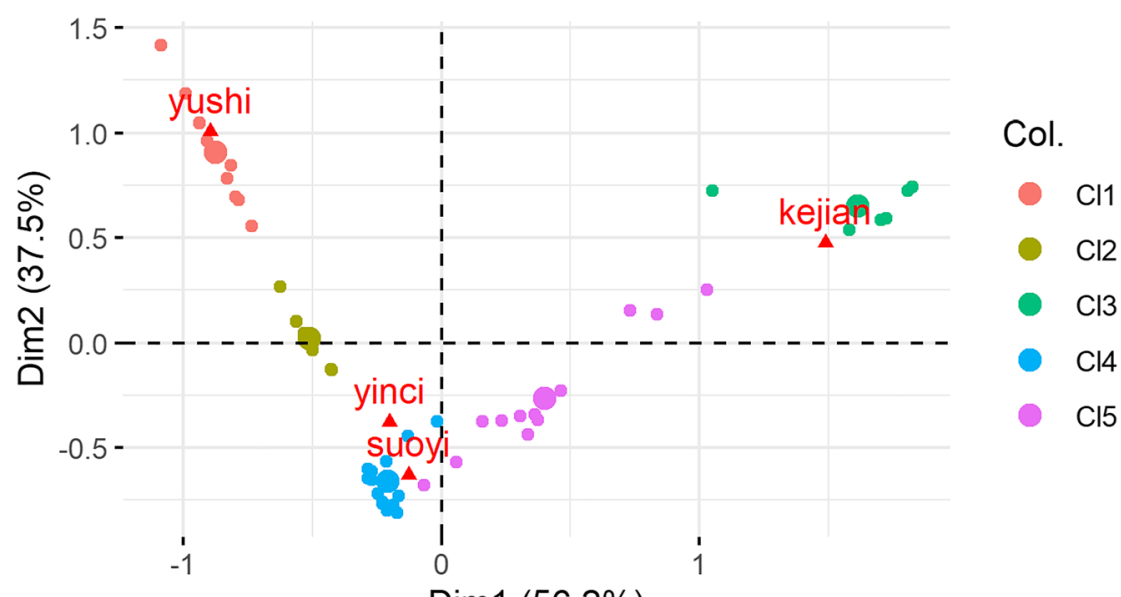

$\operatorname{Dim} 1(56.2 \%)$

Figure 6: Bi-plot from the correspondence analysis on the answer frequencies of the connectives per item; the bi-plot localizes the connectives (represented in their written form) and the items (represented by dots; the dot colors represent the cluster [CI]).

This two-dimensional bi-plot shows a remarkable pattern. First of all, the five clusters have their own spots, filling in the space in the two dimensions. The best description of their distribution seems to be that it is V-shaped. The most important dimension (accounting for $56.2 \%$ of the variation in the data) is 
subjective-objective. On the left side we find the objective relations, on the right side the subjective ones. However, this clear relationship is moderated by the second dimension (which accounts for $37.5 \%$ of the variation): on the lower part of the dimension, we find the items with hedging modals, whereas on the higher part of the dimension we find items that are factive because they concern objective relations or they express a high degree of certainty (cluster 3). All in all, we can interpret this dimension as certainty about the causal event expressed. In sum, it seems that our participants' choices echo what was found in recent studies on Spanish and Mandarin: that intra-sentential characteristics such as modal elements play an important role in accounting for the distribution of causal connectives in Mandarin.

\section{Discussion and conclusion}

In this paper, we tested a cognitive account of subjectivity in causality, by applying it to result connectives in Mandarin. The results indicate how the cognitive principles of subjectivity and causality account for the organization of the causal connective lexicon of Mandarin, suggesting these principles are indeed applicable in a wide range of languages. A methodological innovation is that we used a connective insertion task as an alternative to manual annotation of corpus data to further test the integrated subjectivity account. This task enabled us to tap large numbers of native participants' intuitions about the meaning and use of causal connectives, thus providing insights missing from the existing literature on Mandarin Chinese studies. This method also helps to avoid the potential framework bias and the individual bias that are inherent to expert analysts' judgments in corpus analyses.

The results of the task corroborate earlier corpus-based observations that regard the division of labor between the four connectives as well as their compatibility with "subjective” versus "objective” causal relations. If we look at the models with subjectivity condition as the predictor (Tables A1-A4 in the Appendix), participants clearly preferred kějiàn to express subjective relations, yúshì to express objective relations, and suǒyǐ and yīncǐ to express both categories. The latter two connectives seem to differ in that yinnč has a less subjective profile than suǒyi: the logit coefficients for the objective condition show that the choice of yincǐ $(-0.646$, in Table A4) is more likely than that of suǒyi $(-1.427$, in Table A3). Together, these results convincingly resonate the findings from the corpus studies on the four connectives (Li et al. 2013; Xiao et al. 2021b). Our hypotheses, therefore, were confirmed, which validates the findings from earlier corpus studies. 
A new finding resulting from the cluster analysis in combination with the correspondence analysis is that in addition to the prototypical subjectivity features of a specific causal relation type, there are linguistic elements in the context that contribute to the interpretation of causal events and connectives' use. In-depth analyses of the test items revealed that the presence or absence of modality words in the result segments differ systematically across the clusters. The interpretation of the correspondence analyses connecting clusters of experimental items to connective preferences is that the data are best explained by an interaction between subjectivity and certainty: the patterns indicate that both the subjectivity condition of the causality event and the certainty expressed about the causal event work to determine the connective preferred by the participants.

The "low-certainty" modal expressions occur most often in clusters 4 and 5, which consist of items that attracted nearly exclusively suǒy̌ and yīnč̌. The modality words found in the purely subjective cluster (cluster 3) express a high degree of certainty, or an affirmative attitude toward the conclusion, and here kějiàn is nearly the only connective being used. Yúshì is chosen almost only in the two purely objective clusters 1 and 2, in which no modality words were present (cf. Figure 4 in Section 4.2; Figure 5 in Section 4.3).

Our conclusion is that different types of modality words play a role in influencing participants’ preferences for suǒy̌̌/yīnč̌ versus kějiàn. This converges with the findings in a recent corpus study, in which distinctive collocational patterns were identified in the context of suǒyǐ versus that of kějiàn (Wei et al. 2020).

The co-occurrence patterns of modality words and connectives evidently contribute to our understanding of causal connectives with respect to their expressive function of subjectivity. As linguistic devices expressing the (speaker's) evaluation of, or attitude towards the truth or likelihood of the expressed propositional content (e.g., Nuyts 2001; Sanders and Spooren 1996; Traugott 2011), modality words are bound to qualify the subjectivity/objectivity expressed in an utterance. The fact that the epistemic modality attracts suǒy and yincǐ reflects the underspecified character of the two connectives. Put differently, when the subjective or objective evaluation of the discourse relation is partially lexicalized in epistemic modality words, there is no need to use a specialized connective. Kějiàn stands out as a highly specialized connective for subjective causal construal. The high-certainty or strong attitudinal modals fit in such a subjective context in a way that they reinforce the causal link of the related discourse segments as from a heavily personal perspective. Lastly, the absence of modality words in the objective relations expressed by yúshì is reasonable, considering the unambiguous objective character of yúshì that has been found in both corpus studies and the current experiment study. 
Our findings raise important questions for follow-up studies. The observations with respect to modality words indicate that there is space for further refinement of the subjectivity model presented earlier. That is, we need to further investigate the role of modality words in enabling a finer-grained analysis of, as well as the distinctions between, the connectives with respect to subjectivity. What we have observed echoes Santana's (2019: 145) proposal to see "whether there is a relation between [additional] linguistic elements that express subjectivity and the use of causal connectives analyzed”.

All in all, our study demonstrates that crowdsourcing experimentation is a valuable method to recruit general native informants' detailed judgments about the interpretation of causal event and connective uses. The results show systematic differences with regard to the use of connectives in relations that differ in terms of subjectivity, demonstrating that native speakers (specifically in this study, Mandarin Chinese) make use of subjectivity to encode and decode different types of causal relations in discourse. However, our study strongly suggests that a comprehensive model of subjectivity should include linguistic elements at other places in the discourse than the connectives, because there may be a relation between the subjectivity expressed in connectives and the elements elsewhere in the discourse. There might be a trade-off between these indicators and the use of connectives. For instance, when speakers use modality words to qualify the subjectivity encoded in a causal relation, it may no longer be necessary to use a subjective causal connective. Likewise, when segments in the discourse context do not contain elements evaluating the subjectivity or objectivity of a causal construal, speakers are likely to use a specialized connective to mount the expression of subjectivity/objectivity encoded in a causal relation.

\section{Abbreviations}

$\begin{array}{ll}\text { 3SG } & \text { third person singular } \\ \text { ADV } & \text { adverb(ial) } \\ \text { ASP } & \text { aspect } \\ \text { ATTR } & \text { attributive } \\ \text { AUX } & \text { auxiliary } \\ \text { CLF } & \text { classifier } \\ \text { CONN } & \text { connective } \\ \text { COP } & \text { copula } \\ \text { GEN } & \text { genitive case } \\ \text { MOD } & \text { mood } \\ \text { NEG } & \text { negation } \\ \text { PREP } & \text { preposition } \\ \text { PRT } & \text { particle }\end{array}$




\section{Data availability statement}

The datasets generated and analyzed during the current study are available in Open Science Framework (OSF) at https://osf.io/yz5ek/.

Acknowledgements: We thank Erwin Komen from the Humanities Lab, Faculty of Arts, Radboud University, for his help in implementing the experiment. We also thank the anonymous reviewers for their valuable comments.

\section{Appendix: Results of the generalized linear mixed effect models with condition (subjective or objective) and five-clustering as fixed effect predictors, and with participant and item as random factors (intercepts)}

Each model has by default the first category of the predictor as the reference level (intercept). A positive value of the coefficient indicates that the connective is more likely to be chosen in the corresponding condition or cluster. A negative value of the coefficient indicates that the connective is less likely to be chosen.

\section{Appendix A: Following are results of the binary condition model}

Table A1: Results of generalized linear mixed effect model for the choice of kějiàn versus the rest.

\begin{tabular}{lrrrr}
\hline Fixed effect & Estimate & Std. error & $Z$ & Sig. \\
\hline Intercept & -7.1365 & 0.8158 & -8.747 & $<0.001$ \\
Subjective & 6.271 & 0.9616 & 6.522 & $<0.001$ \\
\cline { 1 - 3 } Random effect & Variance & Std. deviation & & \\
\cline { 1 - 3 } Participant & 0.2051 & 0.4529 & & \\
Item & 6.2317 & 2.4963 & & \\
\hline
\end{tabular}


Table A2: Results of generalized linear mixed effect model for the choice of yúshì versus the rest.

\begin{tabular}{lccrr}
\hline Fixed effect & Estimate & Std. error & $Z$ & Sig. \\
\hline Intercept & -0.9733 & 0.3618 & -2.690 & 0.007 \\
Subjective & -3.7367 & 0.5787 & -6.457 & $<0.001$ \\
\cline { 1 - 2 } Random effect & Variance & Std. deviation & \\
\cline { 1 - 2 } Participant & 0.2777 & 0.527 & \\
Item & 2.9120 & 1.706 & \\
\hline
\end{tabular}

Table A3: Results of generalized linear mixed effect model for the choice of suǒyǐ versus the rest.

\begin{tabular}{lccrr}
\hline Fixed effect & Estimate & Std. error & $\boldsymbol{Z}$ & Sig. \\
\hline Intercept & -1.4265 & 0.2629 & -5.425 & $<0.001$ \\
Subjective & 0.1232 & 0.3696 & 0.333 & 0.739 \\
\hline Random effect & Variance & Std. deviation & \\
\hline Participant & 0.3242 & 0.5693 & \\
Item & 1.4761 & 1.2149 & \\
\hline
\end{tabular}

Table A4: Results of generalized linear mixed effect model for the choice of yīncǐ versus the rest.

\begin{tabular}{lccrr}
\hline Fixed effect & Estimate & Std. error & $Z$ & Sig. \\
\hline Intercept & -0.6464 & 0.2350 & -2.750 & 0.006 \\
Subjective & -0.5039 & 0.3368 & -1.496 & 0.135 \\
\hline Random effect & Variance & Std. deviation & \\
\cline { 1 - 3 } Participant & 0.121 & 0.3478 & \\
Item & 1.222 & 1.1054 & \\
\hline
\end{tabular}

\section{Appendix B: Following are the results of the five-clustering model}

Table B1: Results of generalized linear mixed effect model for the choice of kějiàn versus the rest.

\begin{tabular}{|c|c|c|c|c|}
\hline Fixed effect & Estimate & Std. error & $Z$ & Sig. \\
\hline Intercept & -6.901 & 1.066 & -6.471 & $<0.001$ \\
\hline Clus2 & 1.121 & 1.339 & 0.838 & 0.402 \\
\hline Clus4 & 2.415 & 1.120 & 2.156 & 0.031 \\
\hline Clus5 & 5.900 & 1.100 & 5.366 & $<0.001$ \\
\hline Clus3 & 9.175 & 1.151 & 7.973 & $<0.001$ \\
\hline Random effect & Variance & Std. deviation & & \\
\hline Participant & 0.211 & 0.459 & & \\
\hline Item & 0.839 & 0.916 & & \\
\hline
\end{tabular}


Table B2: Results of generalized linear mixed effect model for the choice of yúshi versus the rest.

\begin{tabular}{lrrrr}
\hline Fixed effect & Estimate & Std. error & $\boldsymbol{Z}$ & Sig. \\
\hline Intercept & 0.994 & 0.237 & 4.190 & $<0.001$ \\
Clus2 & -1.855 & 0.366 & -5.063 & $<0.001$ \\
Clus4 & -4.322 & 0.342 & -12.647 & $<0.001$ \\
Clus3 & -4.765 & 0.494 & -9.656 & $<0.001$ \\
Clus5 & -5.308 & 0.421 & -12.611 & $<0.001$ \\
\cline { 1 - 2 } Random effect & Variance & Std. deviation & & \\
\cline { 1 - 3 } Participant & 0.305 & 0.552 & & \\
Item & 0.400 & 0.632 & & \\
\hline
\end{tabular}

Table B3: Results of generalized linear mixed effect model for the choice of suǒyĭ versus the rest.

\begin{tabular}{lrrrr}
\hline Fixed effect & Estimate & Std. error & $Z$ & Sig. \\
\hline Intercept & -2.566 & 0.235 & -10.913 & $<0.001$ \\
Clus3 & -0.511 & 0.387 & -1.318 & 0.187 \\
Clus2 & 1.016 & 0.339 & 2.998 & 0.003 \\
Clus5 & 1.533 & 0.288 & 5.331 & $<0.001$ \\
Clus4 & 2.484 & 0.279 & 8.914 & $<0.001$ \\
\cline { 1 - 2 } Random effect & Variance & Std. deviation & & \\
\cline { 1 - 3 } Participant & 0.325 & 0.570 & & \\
Item & 0.278 & 0.527 & & \\
\hline
\end{tabular}

Table B4: Results of generalized linear mixed effect model for the choice of yīncǐ versus the rest.

\begin{tabular}{lrrrr}
\hline Fixed effect & Estimate & Std. error & $\boldsymbol{Z}$ & Sig. \\
\hline Intercept & -1.456 & 0.185 & -7.872 & $<0.001$ \\
Clus3 & -2.291 & 0.412 & -5.563 & $<0.001$ \\
Clus5 & 0.995 & 0.236 & 4.219 & $<0.001$ \\
Clus4 & 1.239 & 0.228 & 5.427 & $<0.001$ \\
Clus2 & 1.410 & 0.277 & 5.085 & $<0.001$ \\
\cline { 1 - 2 } Random effect & Variance & Std. deviation & & \\
\cline { 1 - 3 } Participant & 0.119 & 0.345 & & \\
Item & 0.199 & 0.446 & & \\
\hline
\end{tabular}




\section{References}

Andersson, Marta. 2019. Subjectivity of English connectives: A corpus and experimental investigation of result forward causality signals in written language. In Óscar Loureda, Inés Recio Fernández, Laura Nadal \& Adriana Cruz (eds.), Empirical studies of the construction of discourse, 299-317. Amsterdam \& Philadelphia: John Benjamins Publishing Company.

Andersson, Marta \& Sundberg Rolf. 2021. Subjectivity (Re)visited: A corpus study of English forward causal connectives in different domains of spoken and written language. Discourse Processes 58(3). 260-292.

Artstein, Ron \& Massimo Poesio. 2005. Bias decreases in proportion to the number of annotators. In Proceedings of the conference on formal grammar and mathematics of language (FG-MoL), 141-150. Ann Arbor, Michigan: Association for Computational Linguistics.

Artstein, Ron \& Massimo Poesio. 2008. Inter-coder agreement for computational linguistics. Computational Linguistics 34(4). 555-596.

Baayen, R. Harald, Douglas J. Davidson \& Douglas M. Bates. 2008. Mixed-effects modeling with crossed random effects for subjects and items. Journal of Memory and Language 59(4). 390-412.

Carlson, Lynn, Daniel Marcu \& Mary E. Okurowski. 2003. Building a discourse-tagged corpus in the framework of rhetorical structure theory. In Jan van Kuppevelt \& Ronnie W. Smith (eds.), Current and new directions in discourse and dialogue, 85-112. Dordrecht: Springer Netherlands.

Crowdsourcing. n.d. In wikipedia. https://en.wikipedia.org/wiki/crowdsourcing (accessed 14 July 2019).

Cuenca, Maria J. 2013. Causal constructions in speech. In Catherine Bolly \& Liesbeth Degand (eds.), Text-structuring. across the line of speech and writing variation (Corpora and Language in Use series, No. 2), 17-32. Louvain-la-Neuve: Presses Universitaires de Louvain.

Degand, Liesbeth \& Henk Pander Maat. 2003. A contrastive study of Dutch and French causal connectives on the Speaker Involvement scale. In Arie Verhagen \& Jeroen M. van de Weijer (eds.), Usage-based approaches to Dutch, 175-199. Utrecht: LOT.

Guo, Jimao. 2006. 'Yúshì' he 'suǒyǐ' de yitong [A contrastive analysis between yúshì and suǒyì]. Hanyu xuebao [Chinese Linguistics] 4. 27-34.

Hoek, Jet. 2018. Making sense of discourse: On discourse segmentation and the linguistic marking of coherence relations. Utrecht: Utrecht University Doctoral Dissertation. Utrecht: LOT.

Howe, Jeff. 2008. Crowdsourcing: Why the power of the crowd is driving the future of business. New York: Crown Business.

Kawahara, Daisuke, Yuichiro Machida, Tomohide Shibata, Sadao Kurohashi, Hayato Kobayashi \& Manabu Sassano. 2014. Rapid development of a corpus with discourse annotations using two-stage crowdsourcing. In Proceedings of COLING 2014, the 25th international conference on computational linguistics: Technical papers, 269-278. Dublin, Ireland: Dublin City University and Association for Computational Linguistics.

Keller, Rudi. 1995. The epistemic weil. In Dieter Stein \& Susan Wright (eds.), Subjectivity and subjectification: Linguistic perspectives, 16-30. Cambridge: Cambridge University Press.

Knott, Alistair \& Robin Dale. 1994. Using linguistic phenomena to motivate a set of coherence relations. Discourse Processes 18(1). 35-62. 
Knott, Alistair \& Ted Sanders. 1998. The classification of coherence relations and their linguistic markers: An exploration of two languages. Journal of Pragmatics 30(2). 135-175.

Krippendorff, Klaus. 2004. Reliability in content analysis. Human Communication Research 30(3). 411-433.

Langacker, Ronald W. 1990. Subjectification. Cognitive Linguistics 1(1). 5-38.

Le, Sébastien, Julie Josse \& François Husson. 2008. FactoMineR: An R package for multivariate analysis. Journal of Statistical Software 25(1). 1-8.

$\mathrm{Li}$, Fang, Jacqueline Evers-Vermeul \& Ted Sanders. 2013. Subjectivity and result marking in Mandarin: A corpus-based investigation. Chinese Language and Discourse 4(1). 74-119.

Li, Shaoqun. 2012. ‘Kejian' de biaoji gongneng he yufahua guocheng [The marking function of 'kejian' and its grammaticalization]. Journal of Northwest University (Philosophy and Social Sciences Edition) 42(3). 177-179.

Lü, Shuxiang (ed.). 1999. Xiandai hanyu babai ci [Eight hundred words of modern Chinese] (Expanded Edition). Beijing: The Commercial Press.

Lyons, John. 1982. Deixis and subjectivity: Loquor, ergo sum? In Richard J. Jarvella \& Wolfgang Klein (eds.), Speech, place, and action: Studies in deixis and related topics, 101-124. Chichester: John Wiley \& Sons.

Mann, William C. \& Sandra A. Thompson. 1988. Rhetorical structure theory: Toward a functional theory of text organization. Text 8(3). 243-281.

Meier, Einar. 2002. Causal subordination in English and Norwegian. Nordic Journal of English Studies 1(1). 33-64.

Nuyts, Jan. 2001. Subjectivity as an evidential dimensión in epistemic modal expressions. Journal of Pragmatics 33(3). 383-400.

Pander Maat, Henk \& Lisbeth Degand. 2001. Scaling causal relations and connectives in terms of speaker involvement. Cognitive Linguistics 12(3). 211-245.

Pander Maat, Henk \& Ted J. M. Sanders. 2000. Domains of use or subjectivity? The distribution of three Dutch causal connectives explained. In Elizabeth Couper-Kuhlen \& Bernd Kortmann (eds.), Cause, condition, concession, contrast: Cognitive and discourse perspectives, 57-82. Berlin \& New York: Mouton de Gruyter.

Pander Maat, Henk \& Ted J. M. Sanders. 2001. Subjectivity in causal connectives: An empirical study of language in use. Cognitive Linguistics 12(3). 247-274.

Prasad, Rashmi, Nikhil Dinesh, Alan Lee, Eleni Miltsakaki, Livio Robaldo, Aravind K. Joshi \& Bonnie Webber. 2008. The Penn discourse TreeBank 2.0. In Proceedings of the sixth international conference on language resources and evaluation (LREC), 2961-2968. Marrakech, Morocco: European Language Resources Association.

Pusse, Florian, Asad Sayeed \& Demberg Vera. 2016. Lingoturk: Managing crowdsourced tasks for psycholinguistics. In Proceedings of conference of the North American chapter of the association for computational linguistics (NAACL-HLT), 57-61. San Diego, California: Association for Computational Linguistics.

R Core Team. 2017. R: A language and environment for statistical computing. Vienna, Austria: $R$ Foundation for Statistical Computing. Version 3.4.1. Available at: https://www.R-project. org/.

Riezler, Stephan. 2014. On the problem of theoretical terms in empirical computational linguistics. Computational Linguistics 40(1). 235-245.

Sanders, José \& Wilbert Spooren. 1996. Subjectivity and certainty in epistemic modality: A study of Dutch epistemic modifiers. Cognitive Linguistics 7(3). 241-264. 
Rohde, Hannah, Anna Dickinson, Chris Clark, Annie Louis \& Bonnie Webber. 2015. Recovering discourse relations: Varying influence of discourse adverbials. In Proceedings of the EMNLP 2015 workshop on linking models of lexical, sentential and discourse-level semantics, 22-31. Lisboa, Portugal: Association of Computational Linguistics.

Rohde, Hannah, Anna Dickinson, Nathan Schneider, ChristopherClark N. L. , Annie Louis \& Bonnie Webber. 2016. Filling in the blanks in understanding discourse adverbials: Consistency, conflict, and context-dependence in a crowdsourced elicitation task. In Proceedings of the 10th linguistic annotation workshop held in conjunction with ACL 2016 (LAW-X 2016), 49-58. Berlin, Germany: Association for Computational Linguistics.

Sanders, Ted, José Sanders \& Eve Sweetser. 2009. Causality, cognition and communication: A mental space analysis of subjectivity in causal connectives. In Ted Sanders \& Eve Sweetser (eds.), Causal categories in discourse and cognition, 21-60. Berlin: Mouton de Gruyter.

Sanders, Ted \& Wilbert Spooren. 2013. Exceptions to rules: A qualitative analysis of backward causal connectives in Dutch naturalistic discourse. Text \& Talk 33(3). 377-398.

Sanders, Ted \& Wilbert Spooren. 2015. Causality and subjectivity in discourse: The meaning and use of causal connectives in spontaneous conversation, chat interactions and written text. Linguistics 53(1). 53-92.

Sanders, Ted, Wilbert Spooren \& Noordman Leo. 1992. Toward a taxonomy of coherence relations. Discourse Processes 15(1). 1-35.

Sanders, Ted, Wilbert Spooren \& Noordman Leo. 1993. Coherence relations in a cognitive theory of discourse representation. Cognitive Linguistics 4(2). 93-133.

Santana, Andrea. 2019. Is porque more like because or like omdat? An exploration of causality and subjectivity in Spanish backward causal connectives. Utrecht: Utrecht University Doctoral Dissertation. Utrecht: LOT.

Santana, Andrea, Dorien Nieuwenhuijsen, Wilbert Spooren \& Ted Sanders. 2017. Causality and subjectivity in Spanish connectives: Exploring the use of automatic subjectivity analyses in various text types. Discours 20.1-37.

Santana, Andrea, Wilbert Spooren, Dorien Nieuwenhuijsen \& Ted Sanders. 2018. Subjectivity in Spanish discourse: Explicit and implicit causal relations in different contexts. Dialogue \& Discourse 9(1). 163-191.

Santana, Andrea, Wilbert Spooren, Dorien Nieuwenhuijsen \& Ted Sanders. 2021. Spanish native speaker's preference for Porque ('Because'), Ya que ('Since') versus Puesto que ('Given that'): Testing subjectivity theory with crowdsourcing experimentation. Text \& Talk 41(2). 211-237.

Scholman, Merel C. J. \& Vera Demberg. 2017a. Crowdsourcing discourse interpretations: On the influence of context and the reliability of a connective insertion task. In Proceedings of the 11th linguistic annotation workshop, 24-33. Valencia, Spain: Association of Computational Linguistics.

Scholman, Merel C. J. \& Vera Demberg. 2017b. Examples and specifications that prove a point: Identifying elaborative and argumentative discourse relations. Dialogue \& Discourse 8(2). 56-83.

Snow, Rion, Brendan O'Connor, Daniel Jurafsky \& Andrew Ng. 2008. Cheap and fast-but is it good?: Evaluating non-expert annotations for natural language tasks. In Proceedings of the conference on empirical methods in natural language processing, 254-263: Honolulu, Hawaii. Association for Computational Linguistics.

Spooren, Wilbert. 1997. The processing of underspecified coherence relations. Discourse Processes 24(1). 149-168. 
Spooren, Wilbert, Ted Sanders, Mike Huiskes \& Liesbeth Degand. 2010. Subjectivity and causality: A corpus study of spoken language. In Sally Rice \& John Newman (eds.), Empirical and experimental methods in cognitive/functional research, 241-255. Stanford: CSLI Publications.

Stukker, Ninke \& Ted Sanders. 2009. Another ('s) perspective on subjectivity in causal connectives: A usage-based analysis of volitional causal relations. Discours 4. 1-33.

Stukker, Ninke \& Ted Sanders. 2012. Subjectivity and prototype structure in causal connectives: A cross linguistic perspective. Journal of Pragmatics 44(2). 169-190.

Sweetser, Eve E. 1990. From etymology to pragmatics: Metaphorical and cultural aspects of semantic structure. Cambridge: Cambridge University Press.

Traugott, Elizabeth C. 1989. On the rise of epistemic meanings in English: An example of subjectification in semantic change. Language 65(1). 31-55.

Traugott, Elizabeth C. 2010. (Inter) subjectivity and (inter) subjectification: A reassessment. In Kristin Davidse, Lieven Vandelanotte \& Cuyckens Hubert (eds.), Subjectification, intersubjectification and grammaticalization, 29-71. Berlin: Mouton De Gruyter.

Traugott, Elizabeth C. 2011. Modality from a historical perspective. Language and Linguistics Compass 5(6). 381-396.

Wei, Yipu, Willem M. Mak, Jacqueline Evers-Vermeul \& Ted J. M. Sanders. 2020. The use of perspective markers and connectives in expressing subjectivity: Evidence from collocational analyses. Dialogue \& Discourse 11(1). 62-88.

Wu, Zhibiao. 1995. Mandarin Chinese news text LDC95T13. Web download. Philadelphia: Linguistic Data Consortium.

Xiao, Hongling. 2020. Subjectivity, causality and connectives in Mandarin Chinese: Converging evidence from written, spoken and social media discourse. Nijmegen: Radboud University Doctoral Dissertation. Utrecht: LOT.

Xiao, Hongling, Fang Li, Ted J. M. Sanders \& Wilbert P. M. S. Spooren. 2021a. How subjective are Mandarin reason connectives? A corpus study of spontaneous conversation, microblog and newspaper discourse. Language and Linguistics 22(1). 166-210.

Xiao, Hongling, Fang Li, Ted J. M. Sanders \& Wilbert P. M. S. Spooren. 2021b. Suǒyǐ 'so', they are different: An integrated subjectivity account of Mandarin result connectives in conversation, microblog and newspaper discourse. Linguistics 59(4). 1103-1142.

Xing, Fuyi. 2001. Hanyu fuju yanjiu [A study of Chinese complex sentences]. Beijing: The Commercial Press.

Zaidan, Omar F. \& Chris Callison-Burch. 2011. Crowdsourcing translation: Professional quality from non-professionals. In Proceedings of the 49th annual meeting of the association for computational linguistics: Human language technologies, vol. 1, 1220-1229. Portland, Oregon: Association for Computational Linguistics.

Zhao, Xin. 2003. 'Yinci, yushi, cong'er' de duo jiaodu fenxi [A multiple-perspective analysis of yinci, yushi and cong'er]. Yuyan yanjiu [Linguistic Research] 1. 26-34.

Zufferey, Sandrine. 2012. "Car, parce que, puisque" revisited: Three empirical studies on French causal connectives. Journal of Pragmatics 44(2). 138-153. 